\title{
The Effects of Thermal Exposure on the High Temperature Behaviour of a Laser Powder Bed Fused Nickel Based Superalloy C263
}

\author{
R.J. Lancaster ${ }^{1 *}$, S.J. Davies ${ }^{1}$, S.P. Jeffs ${ }^{1}$, D.T.S. Lewis ${ }^{1}$, M.P. Coleman ${ }^{2}$ \\ ${ }^{1}$ Institute of Structural Materials, College of Engineering, Swansea University, Swansea, SA1 8EN, \\ United Kingdom. 656258@ swansea.ac.uk; s.p.jeffs@swansea.ac.uk; d.t.s.lewis@ swansea.ac.uk \\ ${ }^{2}$ Advanced Imaging and Microscopy Facility, College of Engineering, Swansea University, Swansea, \\ SA1 8EN, United Kingdom. m.p.coleman@swansea.ac.uk \\ * Corresponding author: Dr R.J. Lancaster; Tel: +441792295965; Email address: \\ r.j.lancaster@swansea.ac.uk
}

\begin{abstract}
Additive manufacturing (AM) processes are currently being investigated to determine their suitability for wider adoption in the aero engine industry where material consistency and structural integrity are essential. A key driver is the ability of AM to produce near net-shape components and complex geometries, reducing material wastage and traditional processing stages. However, one major limitation remains in the anisotropic structures due to the complex thermal history of the process. Previous studies have employed heat treatment schedules attempting to alleviate such behaviour, although little research is currently available that explores microstructural evolution of AM alloys at in-service temperature conditions. In this research, the effects of thermal exposure on microstructure and mechanical behaviour of Laser Powder Bed Fused (LPBF) C263 is evaluated and assessed against a Cast equivalent. Results show that when exposing Cast and LPBF C263 samples to service temperatures for an extended period of time, the materials experience microstructural and chemical alterations directly controlling the mechanical response. The thermal exposure programme has demonstrated that with the precipitation of carbide phases in the exposed LPBF variant, grain boundary morphologies are highly comparable to the wrought equivalent of the same alloy.
\end{abstract}

Keywords: C263; laser powder bed fusion; thermal exposure; microstructure

\section{Introduction}

The gas turbine is one of the most technologically advanced engineering systems from a component design and metallurgical aspect. To continue to meet safety, environmental and performance targets set within the aerospace sector, it becomes essential that innovative approaches to materials and manufacturing are explored to improve component design and material capabilities. An example of these advanced technologies is additive manufacturing (AM). Considerable effort has been made over the last decade in realising the potential of AM and a wealth of literature is now available documenting the influence of process parameters on the final structure, providing engineers increased confidence when considering such technologies for current and future use [1], [2].

Laser Powder Bed Fusion (LPBF) is a net-shape fabrication technique derived from AM offering many advantages over traditional fabrication methods. However, typical characteristics of LPBF builds can include sensitivity to process parameters, epitaxial grain growth promoting anisotropic structures and residual stresses, in addition to powder and melt defects [3]. Several studies have implemented postprocessing techniques to alleviate some of these features in high performance alloy systems, typically through optimised heat treatments [4], [5]. In previous work by the authors, two alternative heat treatment schedules were applied to LPBF builds of the nickel based superalloy C263 [6]. The standard heat treatment schedule for the alloy, which is typically employed to precipitation strengthen the Cast equivalent, produced a predominantly elongated and textured microstructure. By increasing the solution heat treatment temperature, full recrystallisation, $\Sigma 3$ formation and an irregular precipitation of grain boundary carbides was achieved, which proved key in improving the elevated temperature performance. 
However, when a superalloy is exposed to high temperatures for extended periods of time, additional phases begin to appear which can be disadvantageous to mechanical properties. Due to their atomic arrangement, these are commonly referred to as topologically close-packed (TCP) phases [7]. TCP phases typically form from the breakdown of carbide and $\gamma^{\prime}$ precipitates, the main strengthening mechanism in Ni based alloy systems, particularly when there is high mismatch between the $\gamma$ and $\gamma$ ' phases. Their morphologies are often plate-like or acicular in appearance. TCP phases are considered as detrimental to mechanical performance, in particular ductility and creep performance, for two main reasons; they are inherently brittle, acting as crack initiation sites and due to where they precipitate from, can lead to depletion of strengthening phases such as $\gamma^{\prime}$ and carbides. Examples of TCP phases include $\sigma, \eta$ and laves, to name a few [7]-[9].

In this study, the effects of thermal exposure on the microstructure and mechanical response of LPBF C263 will be studied, bench marked against the Cast equivalent of the same alloy. Various analytical tools will be employed, including advanced electron microscopy and small punch (SP) testing.

\section{Experimental Methods}

\subsection{Material}

To understand the effects of service exposure periods on the microstructure and mechanical response of LPBF C263, samples were soaked at an elevated temperature to simulate conditions within the gas turbine engine. Several LPBF C263 bars were built in the $90^{\circ}$ orientation with a diameter of $9.5 \mathrm{~mm}$, $70 \mathrm{~mm}$ in length. The chemical composition for the material is given in Table 1 . The bars were built with Rolls-Royce plc. standard parameters and were subjected to the higher temperature heat treatment regime, here onwards recognised as HT2. The HT2 schedule consists of a higher temperature solution heat treatment of $1275^{\circ} \mathrm{C}$ for 2 hours before air cooling, followed by an ageing heat treatment of $800^{\circ} \mathrm{C}$ for 8 hours.

Prior to the extended thermal exposure, the central portion of the rods were sectioned into pieces approximately $25 \mathrm{~mm}$ in length with a Struers Secotom-10 and an Aluminium Oxide cutting wheel. These cylindrical off-cuts were then placed into a box furnace for a duration of 500 hours at $850^{\circ} \mathrm{C}$ to replicate a predicted upper-bound service temperature condition. The furnace had been previously soaking at temperature for 1 hour before introducing the bars to the chamber. Samples were then left to air cool following the exposure period. Non-solution heat treated cylinders of cast C263 were exposed to the same conditions to provide direct comparisons to HT2 material. The composition of cast C263 is also given in Table 1.

Table 1. Chemical composition of LPBF and cast C263 material used for thermal exposure investigations (wt\%)

\begin{tabular}{ccccccccccc}
\hline LBPF & $\mathbf{N i}$ & $\mathbf{C o}$ & $\mathbf{C r}$ & $\mathbf{M o}$ & $\mathbf{T i}$ & $\mathbf{A l}$ & $\mathbf{C}$ & $\mathbf{M n}$ & $\mathbf{S i}$ & $\mathbf{N b}$ \\
& Bal. & 19.7 & 19.8 & 5.7 & 2.02 & 0.47 & 0.04 & 0.1 & 0.05 & 0.14 \\
\cline { 2 - 11 } & $\mathbf{F e}$ & $\mathbf{C u}$ & $\mathbf{B}$ & $\mathbf{A g}$ & $\mathbf{B i}$ & $\mathbf{W}$ & $\mathbf{P b}$ & $\mathbf{S}$ & $\mathbf{O}$ & $\mathbf{N}$ \\
& 0.06 & $<0.001$ & 0.0004 & $<0.0005$ & $<0.0001$ & $<0.01$ & $<0.001$ & 0.002 & 0.018 & 0.004 \\
\hline \multicolumn{1}{c}{ Cast } & $\mathbf{N i}$ & $\mathbf{C o}$ & $\mathbf{C r}$ & $\mathbf{M o}$ & $\mathbf{T i}$ & $\mathbf{A l}$ & $\mathbf{C}$ & $\mathbf{M n}$ & $\mathbf{B}$ & $\mathbf{Z r}$ \\
& $\mathrm{Bal}$. & 20.0 & 20.0 & 5.9 & 2.1 & 0.5 & 0.06 & 0.1 & 0.001 & 0.02 \\
\hline
\end{tabular}

Prior to analysing the level of oxidation in the exposed microstructures, a gold sputter coating was applied to each specimen, followed by nickel plating to protect the oxide layers prior to mounting the material in Bakelite. Samples were then hand polished using progressively finer SiC grinding papers between 220grit and 1200grit, prior to machine polishing with a Struers Labopol-5 auto-polisher where successively finer polishing surfaces and mediums were used. Samples were finished with a Struers MD-Chem polishing cloth with $0.02 \mu \mathrm{m}$ OP-S suspension to achieve a mirror finish. Polishing for 
advanced SEM, Electron Back-Scatter Diffraction (EBSD) and carbide analysis was finalised using a Chem polishing cloth mounted on a Buehler VibroMet polisher with $0.02 \mu \mathrm{m}$ OP-S suspension.

\subsection{Microscopy}

Large scale optical micrographs were captured for each variant to provide confidence that the sampled regions presented are representative of the overall material microstructure. Microscopy of oxide damage and service induced phases was performed using a JEOL 7800F FEG-SEM along with an Oxford Instruments SMax 50 to capture Energy Dispersive X-ray Spectroscopy (EDS) data. For all samples, 10 independent micrographs of oxidation layers were collected for oxide damage measurements. From each micrograph, five measurements were taken from each individual oxide layer.

\subsection{Mechanical Testing}

The influence of temperature exposure on mechanical performance was determined through SP testing. SP discs of $9.5 \mathrm{~mm}$ diameter were sectioned from both exposed and non-exposed regions of Cast and LPBF C263 rods and ground with successive grades of Silicon Carbide papers, finishing with 1200grit, to a thickness of $500 \pm 5 \mu \mathrm{m}$. This procedure is in direct accordance to the European Code of Practice for Small Punch Testing (EUCoP) [10] and the forthcoming European Standard [11].

SP tests were performed with a bespoke jig manufactured from Nimonic-90 to allow for high temperature testing. The SP disc specimen is clamped between an upper and lower die, subjected to loading via a $\varnothing 2.5 \mathrm{~mm}$ hemispherical indenter punch towards the centre of the specimen, deforming it through a chamfered $\emptyset 4 \mathrm{~mm}$ receiving hole, in line with the specifications given in the EUCoP. Disc displacement is measured from the cross-head of the test frame and deflection is recorded via a single linear variable displacement transducer (LVDT) measuring the deformation of the lower side of the specimen via a hollow quartz rod. For the purposes of this research, deflection $(D)$ behaviour will be compared against force $(F)$. The quartz rod is positioned to maintain contact between the LVDT and the disc face, compressing the LVDT as the disc deforms. For elevated temperature SP testing, a Ntype thermocouple is positioned within the hollow quartz rod used for deflection measurements to allow direct contact with the disc specimen. The furnace, with control thermocouples in-situ, is positioned surrounding the test jig so the specimen is placed in a central location. Test temperatures were monitored throughout each experiment to ensure they fell within $\pm 0.25 \%$ of the intended temperature in degrees absolute, ${ }^{\circ} \mathrm{K}$. Tests were performed at room temperature (RT) and $780^{\circ} \mathrm{C}$ with displacement rates of $0.3 \mathrm{~mm} \cdot \mathrm{min}^{-1}$.

\section{Results \& Discussion}

\subsection{Effect of Thermal Exposure on Microstructure}

The microstructures of the Cast and LPBF C263 materials both pre and post-exposure are presented in Figures 1 and 2. The images were captured using band contrast and grain boundary EBSD maps displaying the effects of the thermal exposure. Statistics obtained from the analysis of these materials are given in Table 2. Figure 1a) presents the bimodal microstructure apparent in the cast C263 variant. From this sample area, the exposed Cast microstructure in Figure 1b) exhibited a microstructure comparable to the coarse grain structure in the original Cast material, with only minor indications of recrystallisation, resulting in a lower percentage of $\Sigma 3$ boundaries and extended random grain boundary network (RGBN) segment lengths. RGBNs are considered as the preferential path for crack propagation where intergranular failure is the dominant growth mechanism. As such the RGBN has been quantified. The average local misorientation angle was found to be lower in the exposed material. Nonetheless, grain sizes and aspect ratios are comparable between exposed and non-exposed Cast C263. 

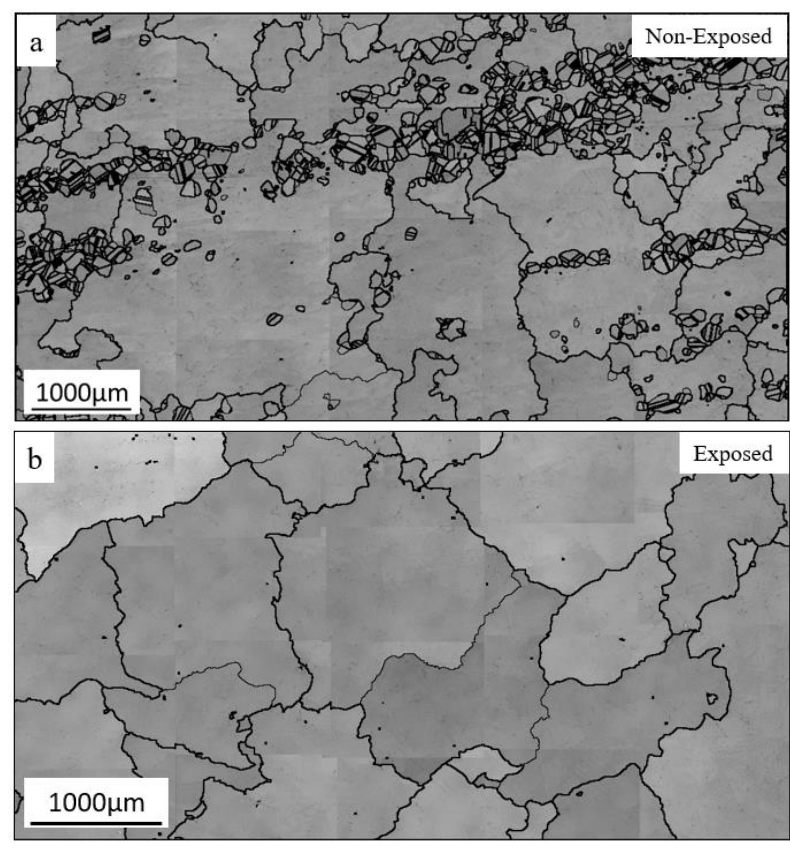

Figure 1. Band contrast and grain boundary EBSD maps exhibiting the microstructures present in Cast C263; (a) non-exposed, (b) exposed for 500 hours at $850^{\circ} \mathrm{C}$.

In the microstructures for the LPBF variant (Figure 2), clear similarities are seen between the exposed and non-exposed conditions, with grain sizes and aspect ratios supporting this. The micrograph in Figure 2c) presents grain boundary carbides which have formed in the non-exposed LPBF material, with EDS revealing increases in Ti and Mo compared with the bulk composition, as was also observed by the authors in separate LPBF C263 builds subjected to HT2 [6]. A marginally lower $\Sigma 3$ percentage and longer average RGBN segment length were found in the exposed condition. Local average misorientation angles were close to identical between the exposed and non-exposed HT2 variants, whereas Cast C263 had experienced a reduction in local average misorientation after temperature exposure according to these datasets.
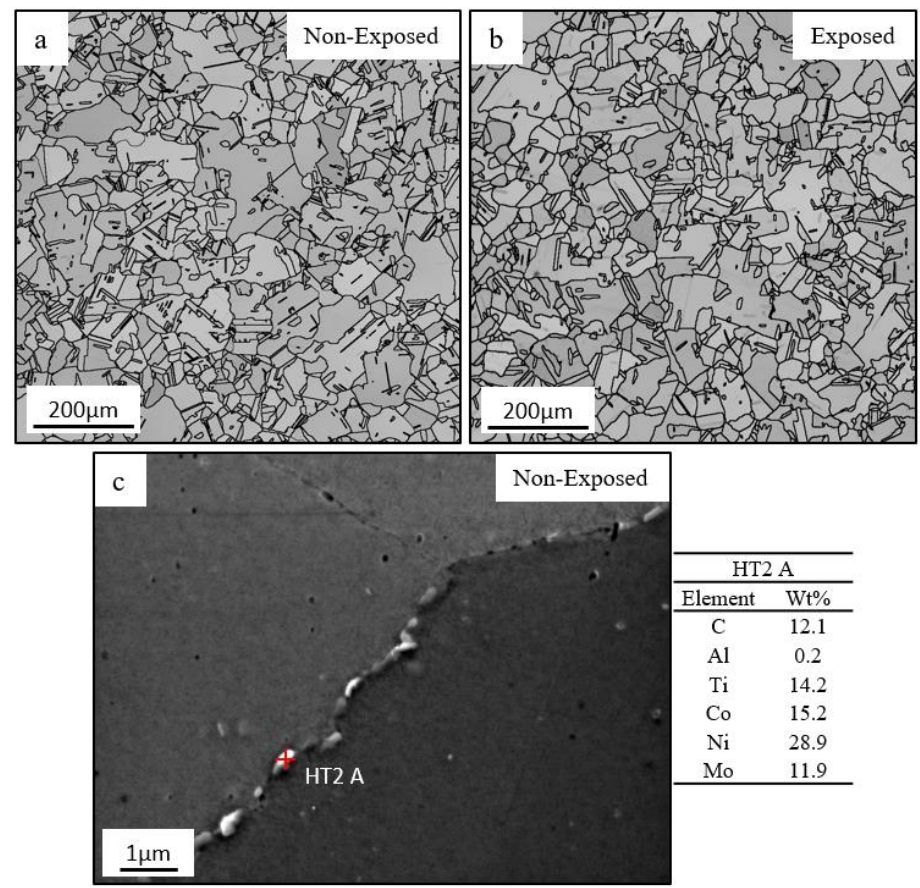

Figure 2. Band contrast and grain boundary EBSD maps exhibiting microstructures of $\mathrm{HT} 290^{\circ} \mathrm{LPBF}$ $\mathrm{C} 263$ (a) non-exposed, (b) exposed for 500 hours at $850^{\circ} \mathrm{C}$. (c) Micrograph of grain boundary carbides in non-exposed $\mathrm{C} 263$. 
Table 2. A comparison of microstructural statistics for Cast and HT2 LPBF C263 in both the temperature exposed and non-exposed conditions. Average grain diameter and grain aspect ratio measurements are provided for the bimodal grain size seen in the non-exposed Cast material

\begin{tabular}{lcccccc}
\hline $\begin{array}{c}\text { C263 } \\
\text { Type }\end{array}$ & Condition & $\begin{array}{c}\text { Avg. Grain } \\
\text { Diameter } \\
(\boldsymbol{\mu m})\end{array}$ & $\begin{array}{c}\text { Grain } \\
\text { Aspect } \\
\text { Ratio }\end{array}$ & $\begin{array}{c}\boldsymbol{\Sigma} 3 \\
(\boldsymbol{\%})\end{array}$ & $\begin{array}{c}\text { RGBN Avg. } \\
\text { Segment } \\
\text { Length }(\boldsymbol{\mu m})\end{array}$ & Avg. KAM $\left(^{\circ}\right)$ \\
\hline Cast & Non-Exposed & $939 / 106$ & $0.55 / 0.56$ & 29.0 & 250 & 0.28 \\
& Exposed & $1197 / 164$ & $0.58 / 0.47$ & 2.7 & 1073 & 0.21 \\
\hline HT2 & Non-Exposed & 59.55 & 1.00 & 71.3 & 15 & 0.16 \\
$\mathbf{9 0}^{\circ}$ & Exposed & 55.76 & 0.92 & 64.5 & 21 & 0.17 \\
\hline
\end{tabular}

The microstructural statistics such as grain size, grain aspect ratio and $\Sigma 3$ percentages were largely unchanged following thermal exposure. This is attributed to the fact that local strain and/or temperature is not sufficient to activate further coarsening of grains [12], or the variants are already in a low energy state. Furthermore, although much of the microstructural attributes can be seen to differ in Cast C263 between the exposed and non-exposed conditions according to Table 2, this is not considered to be a consequence of the thermal exposure heat treatment. Rather, this is likely due to the sampled regions in this variant, which had already demonstrated a changeable microstructure prior to exposure.

\subsection{Characterisation of Oxide Damage}

Oxide layers were developed on sample surfaces of both variants after thermal exposure, as presented in the micrographs in Figure 3. EDS helped to determine the distribution of constituents present to establish the oxide layer types; these results are included in Figures 4 and 5. The Au layer highlighted in both variants is the result of the gold sputter process, effectively marking the outer boundary of the material oxidation. Below this boundary, a Ni-oxide layer had formed, also consisting of $\mathrm{Co}$ and $\mathrm{Cu}$ in Cast C263 and Co and Fe in LPBF C263. This has been termed the 'outer-oxide scale'. A thinner Croxide scale or chromia layer formed in both material variants below the outer-oxide scale, typical of $\mathrm{Ni}$ superalloys with similar amounts of $\mathrm{Cr}$ [13]. This layer was followed by the development of alumina fingers, forming preferentially along grain boundaries [13], [14]. The Cr map in Figure 4 reveals the depletion of grain boundary carbides resulting from alumina growth [14]. Similar behaviour was seen by Lewis et al [15] on the nickel based superalloy RR1000, where grain boundary carbide depletion occurred due to $\mathrm{Cr}$ migration from the $\mathrm{MC}$ and $\mathrm{M}_{23} \mathrm{C}_{6}$ carbides which formed an oxide scale at the surface. Here, the alumina fingers are not as evident due to the reduced aluminium alloying content. Oxide layer thickness measurements are recorded and compared in Table 3.
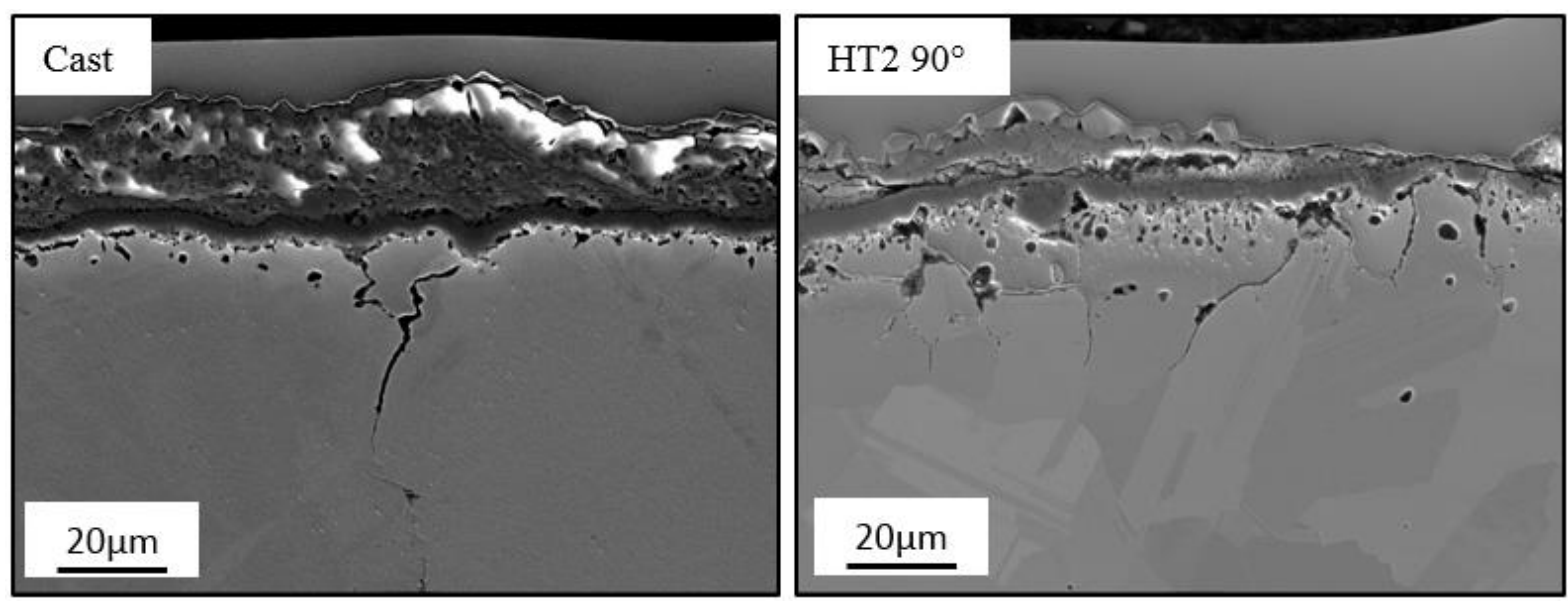

Figure 3. Micrographs exhibiting oxidation damage caused by exposure at $850^{\circ} \mathrm{C}$ for 500 hours on the surfaces of (a) Cast and (b) HT2 90 $\mathrm{C} 263$ samples. 


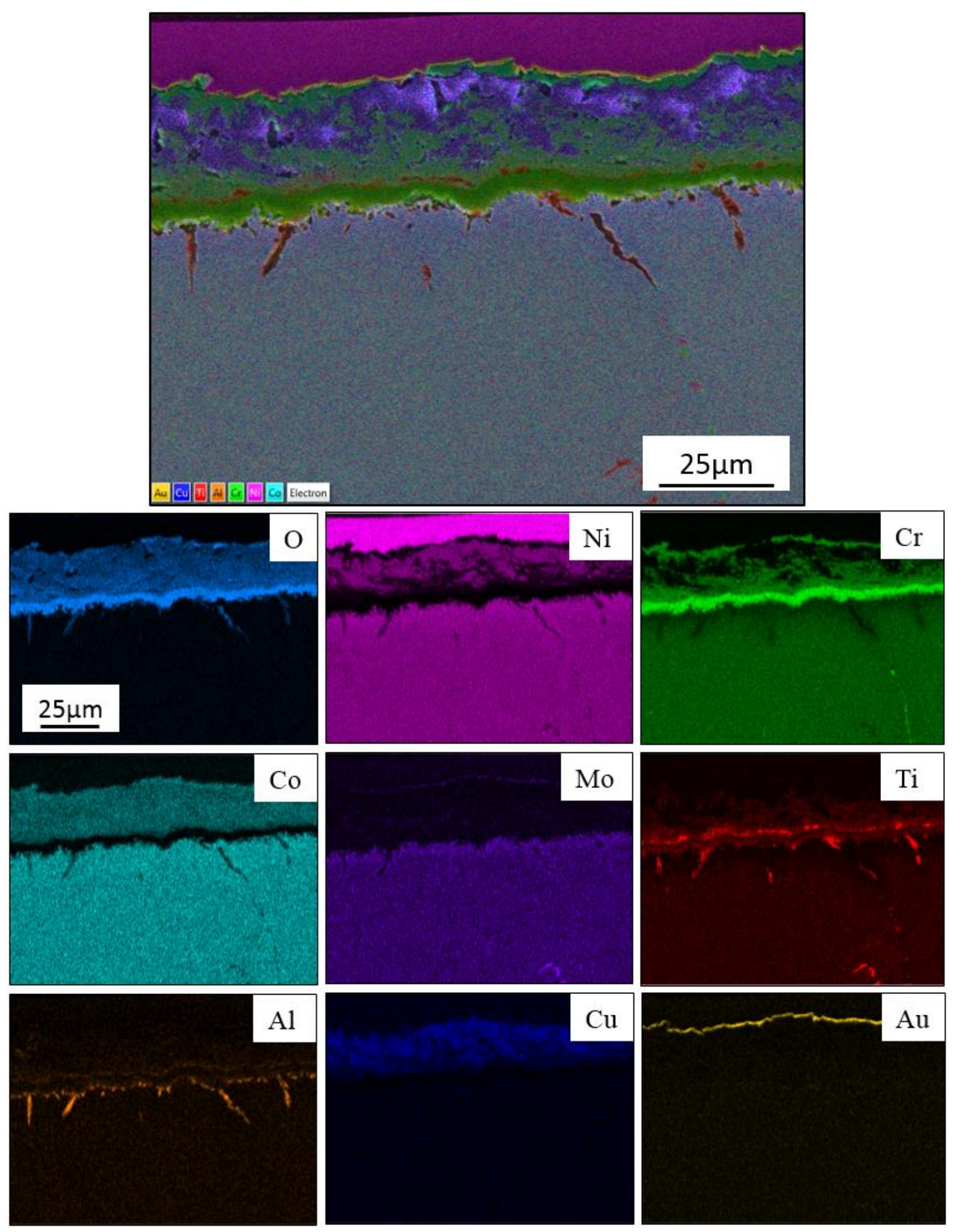

Figure 4. EDS layer map with individual element maps revealing typical oxide damage layering in Cast $\mathrm{C} 263$ following exposure to $850^{\circ} \mathrm{C}$ for 500 hours. 


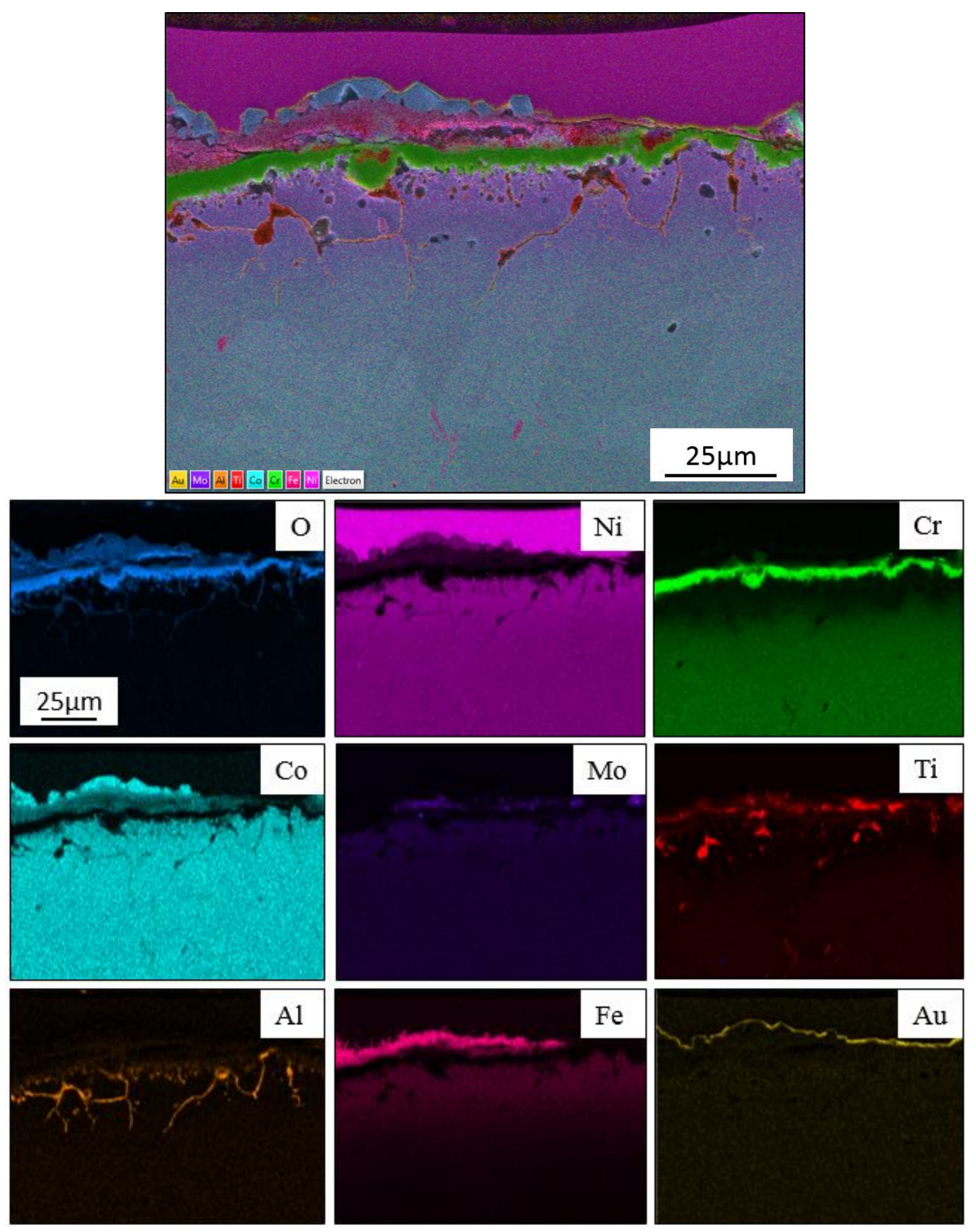

Figure 5. EDS layered map with individual element maps showing typical oxide damage layering in $\mathrm{HT} 290^{\circ} \mathrm{LPBF} \mathrm{C} 263$ following exposure to $850^{\circ} \mathrm{C}$ for 500 hours.

From the oxide layer measurements, comparisons could be made between Cast and LPBF C263, particularly between the outer oxide scales and chromia layers. However, most differences in oxidation behaviour were found in the alumina formation. LPBF C263 developed larger and more consistent alumina finger depths compared with the Cast material, as detailed in Table 4, where values represent the oxide layer sizes as ratios, normalised by the specific variant's chromia thicknesses, emphasising the enhanced alumina formation in the LPBF variant. 
Table 3. Measurements of key oxide damage layers found in both Cast and LPBF C263 following exposure to temperature.

\begin{tabular}{cccccc}
\hline $\begin{array}{c}\text { Oxide Damage } \\
\text { Layer }\end{array}$ & C263 Type & $\begin{array}{c}\text { Average Scale Thickness } \\
\text { / Depth }(\boldsymbol{\mu m})\end{array}$ & $\begin{array}{c}\text { Standard } \\
\text { Deviation }\end{array}$ & $\begin{array}{c}\text { Max. } \\
(\boldsymbol{\mu m})\end{array}$ & $\begin{array}{c}\text { Min. } \\
(\boldsymbol{\mu m})\end{array}$ \\
\hline \multirow{2}{*}{ Cr-Oxide Scale } & Cast & 4.33 & 0.95 & 6.96 & 2.16 \\
& HT2 $90^{\circ}$ & 4.64 & 1.17 & 8.23 & 2.63 \\
\hline \multirow{2}{*}{ Al-Oxide Scale } & Cast & 14.93 & 12.13 & 49.66 & 2.34 \\
& HT2 90 & 29.07 & 8.20 & 51.71 & 16.12 \\
\hline Outer Oxide & Cast & 14.88 & 7.94 & 28.41 & 0.77 \\
Scale & HT2 90 $90^{\circ}$ & 16.62 & 8.76 & 36.79 & 3.19 \\
\hline
\end{tabular}

Table 4. Ratio of oxide damage layer thicknesses in both exposed variants to compare layer development (normalised by Cr scale depth).

\begin{tabular}{cccc}
\hline C263 Type & Cr-Oxide Scale & Al-Oxide Scale & Outer Oxide Scale \\
\hline Cast & 1 & 3.45 & 3.44 \\
HT2 90 $^{\circ}$ & 1 & 6.27 & 3.58 \\
\hline
\end{tabular}

The results confirm that the LPBF variant exhibits noticeably more developed alumina growth but the Cast material contains far higher variance in the alumina layer measurements. With the significantly contrasting grain sizes between Cast and HT2 C263, this leads to a considerable difference in surface grain boundary densities. The alumina forms predominantly in intergranular regions, hence, in LPBF C263 where surface grain boundaries are prominent, preferential alumina growth develops more substantially than in Cast C263 where surface grain boundary presence is more sparse and irregular. The impact on the mechanical performance due to the differences in alumina growth remains unknown due to the peripheral disc clamping during SP testing. However, as oxide damage causes embrittlement in these alloys, it can be expected that under uniaxial test conditions, surface regions may act as an area for crack initiation, thus degrading mechanical integrity [13]. This was evidenced from a series of five low load hardness indentations on the exposed variants, which showed a significant increase in $\mathrm{Hv}$ and standard deviation in the oxide layer (Cast $=599 \pm 58 \mathrm{Hv}, \mathrm{LPBF}=796 \pm 40 \mathrm{Hv}$ ) compared to the base material (Cast $=259 \pm 7 \mathrm{Hv}, \mathrm{LPBF}=282 \pm 16 \mathrm{Hv}$ ). Here, a reduced load of $20 \mathrm{gf}$ was used due to the cracking observed in the oxide layers under higher applied loads, as shown in Figure 6.
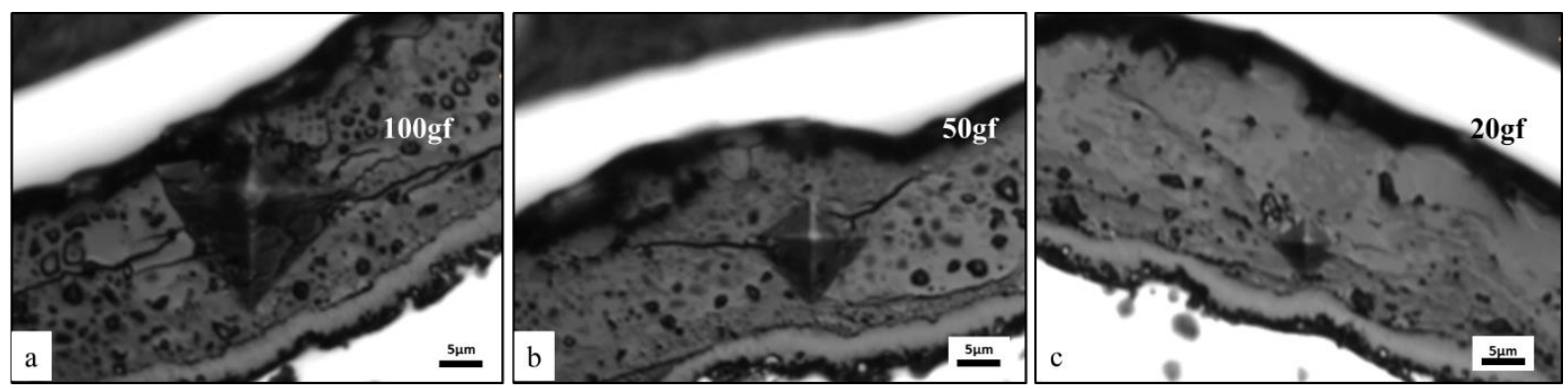

Figure 6. Hardness indentations on exposed Cast C263 under a)100gf, b) 50gf and c) 20gf.

\subsection{Sub-Surface Features Resulting from Exposure}

The thermal exposure programme also resulted in microstructural transformations within the bulk material. Figure 7 reveals the effects on grain boundary precipitates. As well as evidence of carbide coarsening (Figure 7b)), many carbides have deteriorated to form TCP phases, likely of the form $\sigma$ or $\mu$-phase [9], since these can form at grain boundary regions and grow in needle-like morphologies. In intragranular regions, acicular phases forming in a Widmanstätten pattern were discovered in exposed Cast C263 as presented in the micrograph in Figure 8. Given their location, morphology and presence of $\mathrm{Ti}$ (as evidenced in Figure 9) with depleted regions of $\gamma^{\prime}$, these are likely $\eta$-phase [16]. 

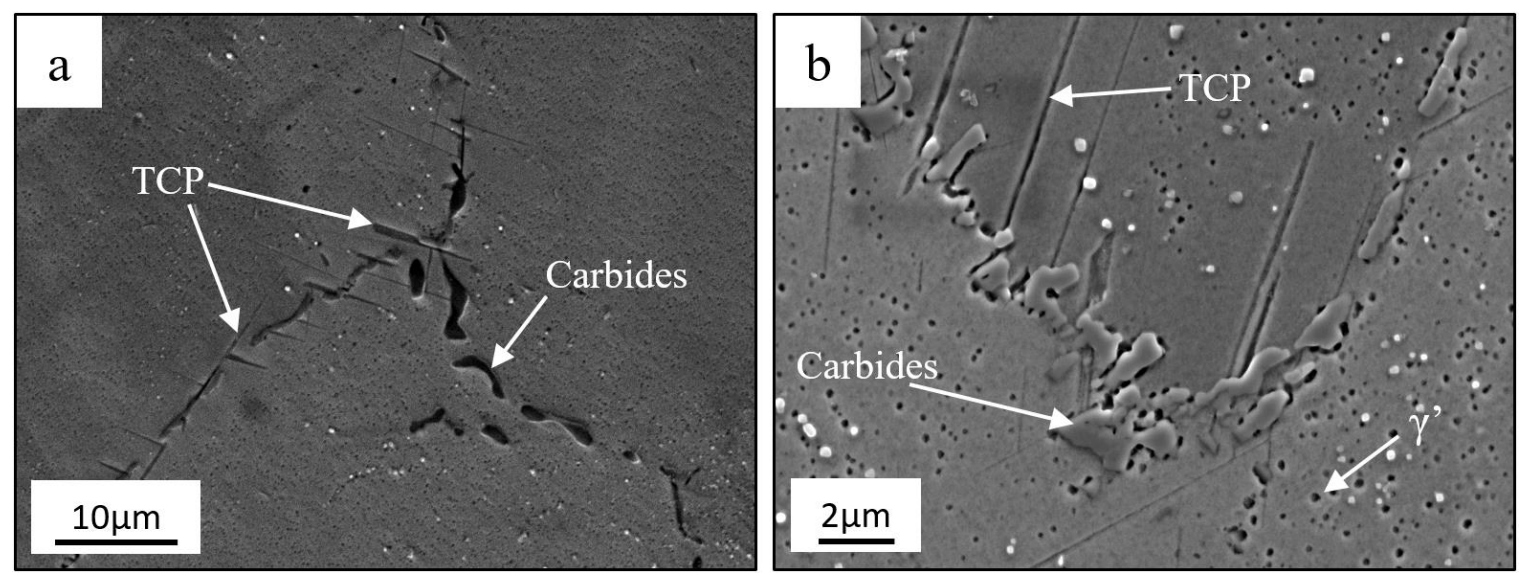

Figure 7. Micrographs displaying the breakdown of grain boundary carbides to form TCP phases in Cast C263 resulting from thermal exposure.

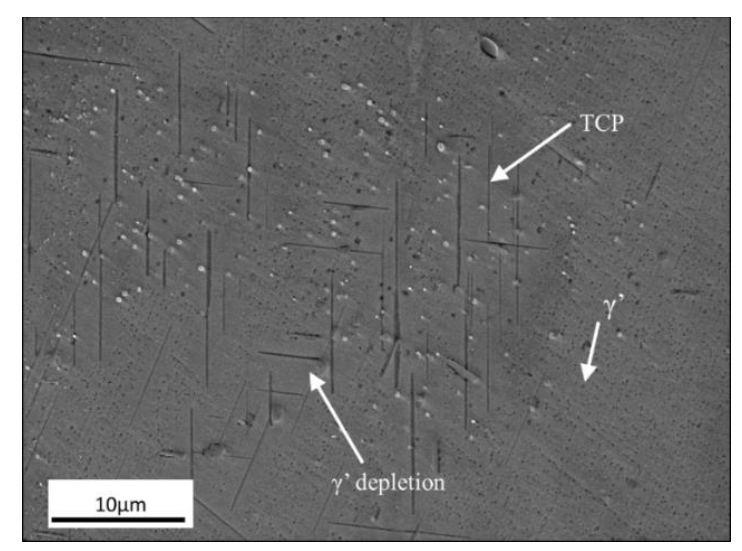

Figure 8. Micrograph displaying depletion of $\gamma^{\prime}$ to form $\eta$-phase.

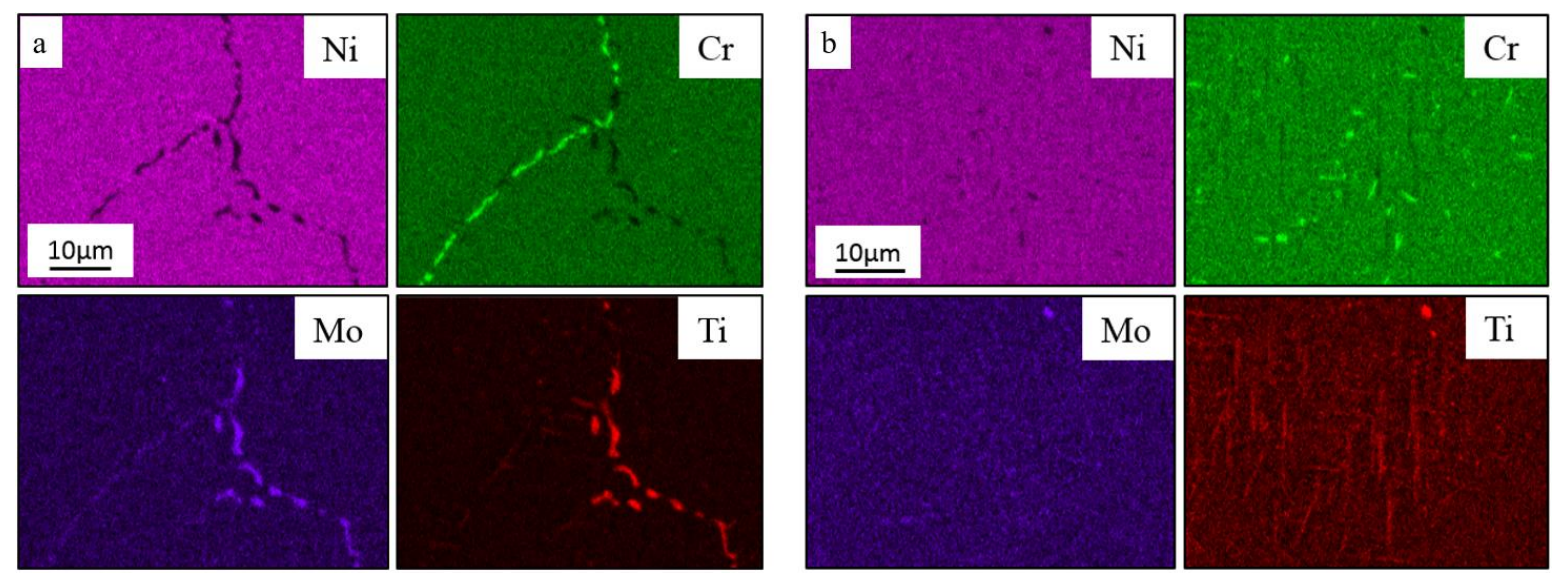

Figure 9. EDS maps to show elemental distribution in a) grain boundary carbides and TCP phases corresponding to the micrograph in Figure 7a) and b) phases corresponding to the micrograph in Figure 8 , supporting their identification as $\eta$-phase.

Figure 10 reveals the microstructural features present in the exposed LPBF material sub-surface. Figure $10 \mathrm{a})$ and b) display TCP phases located on various grain boundaries. Although TCP phases were present at grain boundaries, a large proportion of the bulk microstructure exhibited the grain boundary phases displayed in Figure 10c) and d). Given the detection of $\mathrm{Cr}$ within these phases (Figure 11), they are likely $\mathrm{M}_{23} \mathrm{C}_{6}$ carbides. 

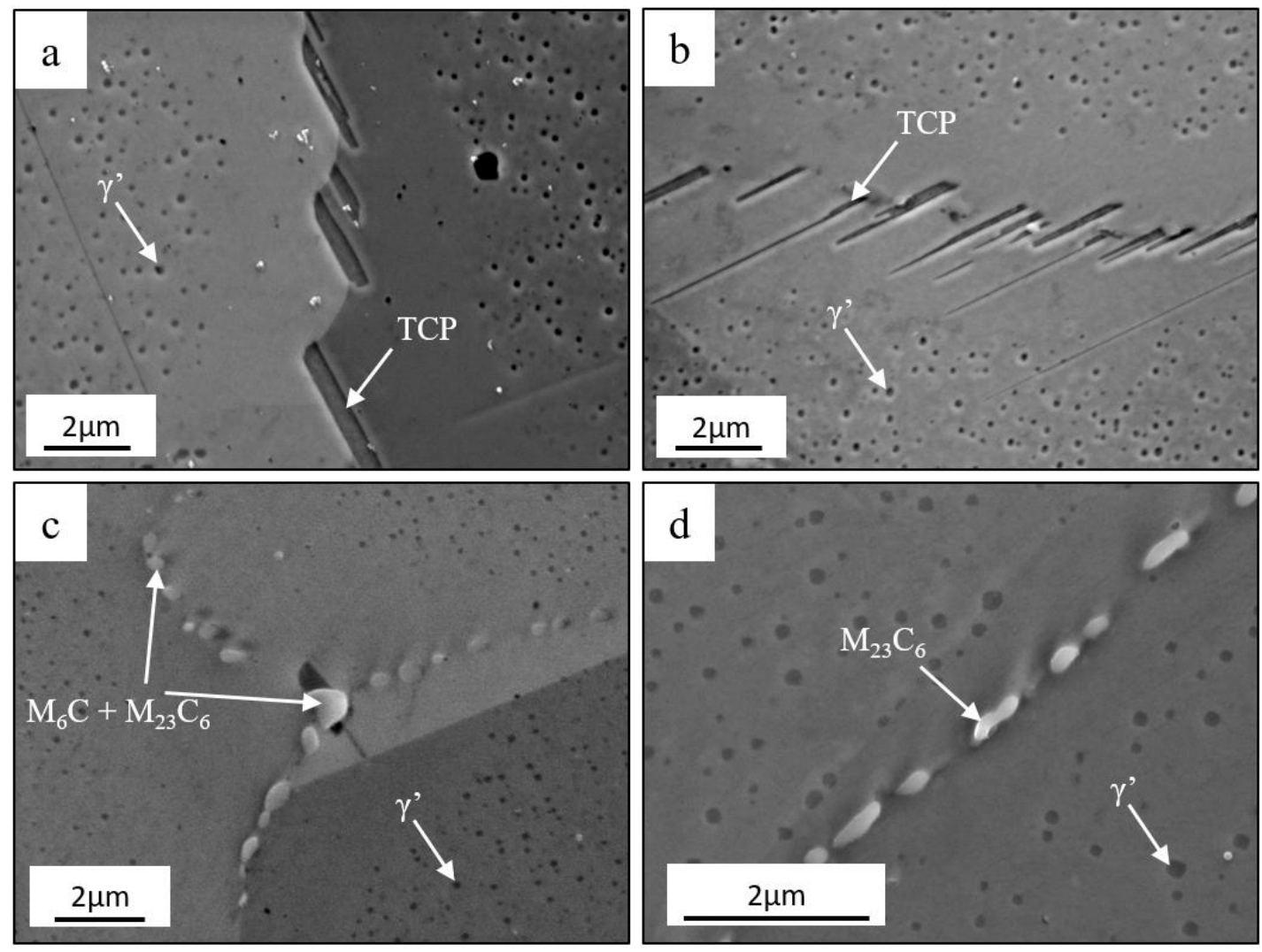

Figure 10. Micrographs displaying the precipitation of $\mathrm{C} 263$ phases and $\gamma^{\prime}$ coarsening resulting from thermal exposure in LPBF C263; (a)(b) formation of TCP phases and $\gamma^{\prime}$ depletion, (c)(d) development of $\mathrm{M}_{23} \mathrm{C}_{6}$ carbides on grain boundaries.
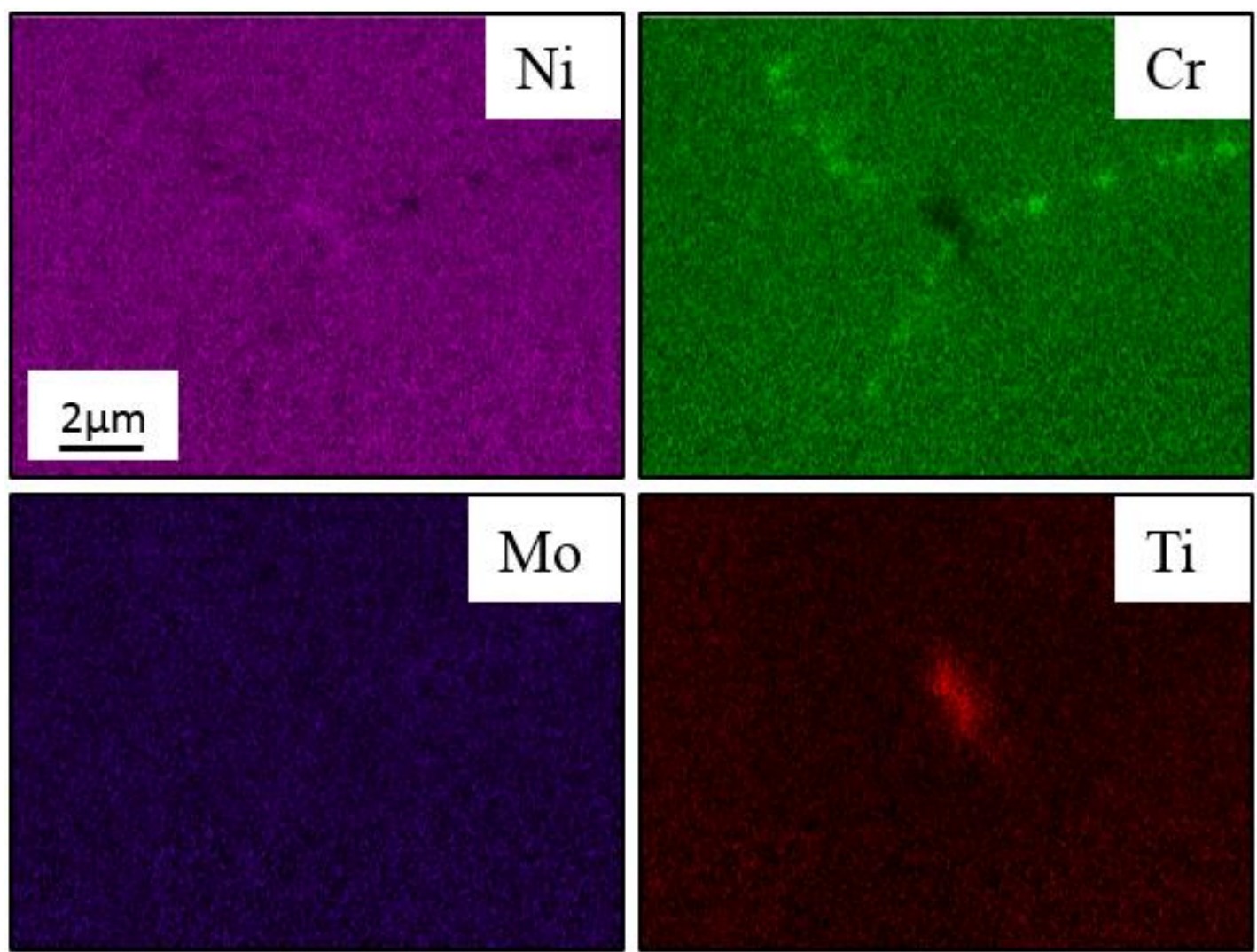

Figure 11. EDS maps revealing the elemental distribution in carbides discovered on exposed LPBF C263 grain boundaries. 
Following an examination of bulk material and grain boundary features, it was discovered that the precipitation of resulting phases, encouraged by thermal exposure, consequently produced dissimilarities between Cast and LPBF microstructures in the exposed condition. Firstly, although $\gamma^{\prime}$ coarsening was evident in both variants, intragranular $\gamma^{\prime}$ depleting TCP phases were only noticed in the exposed Cast material. Although difficult to confirm at the resolutions available in this study, this supports the understanding that a fully developed array of $\gamma^{\prime}$ precipitation may not be present in the non-exposed condition of LPBF C263. Whereas, in the Cast material, where there is an established level of $\gamma^{\prime}$ precipitation expected, TCP phases form from the breakdown of already present $\gamma^{\prime}$ [17], [18]. In the LPBF variant, it is suggested that the thermal exposure has merely encouraged initial or early stage $\gamma^{\prime}$ precipitation to reach a mature state before $\gamma^{\prime}$ can deteriorate to form TCP phases.

At grain boundaries, TCP development from the breakdown of grain boundary carbides was observed, including carbide coarsening in some regions. This was found to be more consistent along Cast C263 grain boundaries than in LPBF C263, where a regular dispersion of $\mathrm{M}_{23} \mathrm{C}_{6}$ carbides was apparent along intergranular regions in non-exposed Cast material, whereas, only what is thought to be $\mathrm{MC}$ and $\mathrm{M}_{6} \mathrm{C}$ carbides were discovered in the HT2 variant. As was previously discussed regarding the breakdown of $\gamma^{\prime}$ to form TCP phases, carbides in Cast $\mathrm{C} 263$, in particular $\mathrm{M}_{23} \mathrm{C}_{6}$, are in a mature enough state so that upon the application of temperature for an extended period of time, they readily decompose to form TCP phases [9], [19]. In LPBF C263, carbides are still in their infancy, harnessing the potential to breakdown to form other carbide types before becoming TCP phases. In areas where carbides are matured, TCP phases precipitate, whereas, in other areas they breakdown to form $\mathrm{M}_{23} \mathrm{C}_{6}$ carbides [8], [16]. With some areas of LPBF material forming only what is thought to be $\mathrm{M}_{23} \mathrm{C}_{6}$ carbides, the exposed variant (as shown in Figure 10c) and d)) demonstrated that it is possible to produce grain boundary morphologies that are comparable to conventionally processed wrought material, as presented in Figure 12 [20]; this is a promising aspect regarding the potential application of an LPBF manufactured advanced alloy and induces interest to further investigate the effects of heat treatment programmes in these materials.

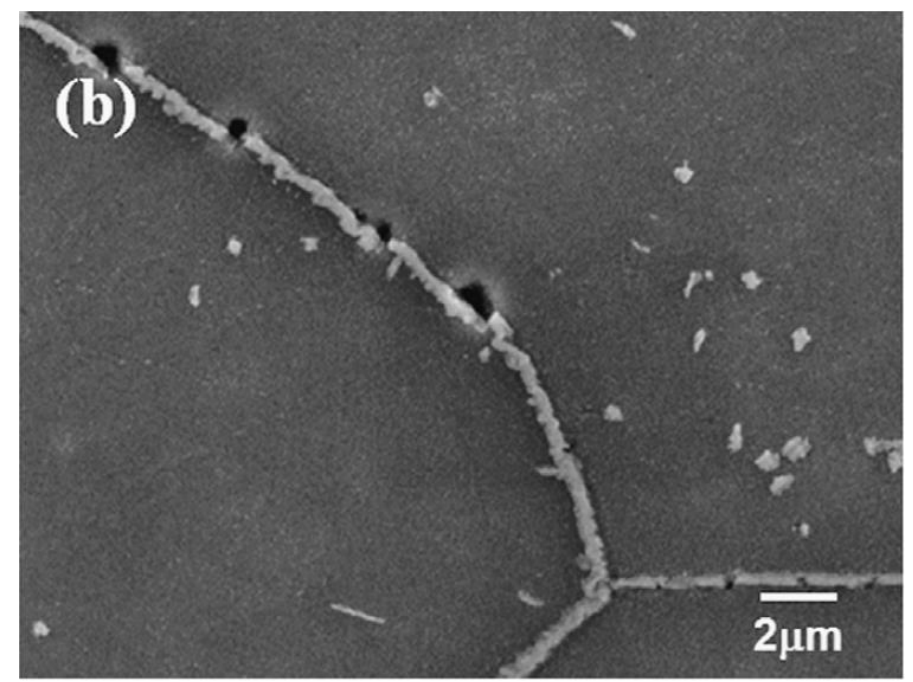

Figure 12. Microstructure of wrought Alloy 263 thermally exposed to $700^{\circ} \mathrm{C}$ for 2000 hours. Reproduced from [20].

\subsection{Mechanical Properties}

Room temperature SP results are displayed in Figure 13. Cast C263 experienced a 51\% reduction in average $F_{\max }$ in the exposed condition, whereas the LPBF variant saw a $33 \%$ increase in average $F_{\max }$ resulting from temperature exposure. The $780^{\circ} \mathrm{C} \mathrm{SP}$ results are exhibited in Figure 13b). Contrary to room temperature results, Cast $\mathrm{C} 263$ experienced an $83 \%$ increase in average $F_{\max }$ in the exposed condition at the elevated test temperature. Exposed LPBF C263 saw only an $18 \%$ increase in $F_{\max }$ in comparison with the non-exposed version of this variant. 

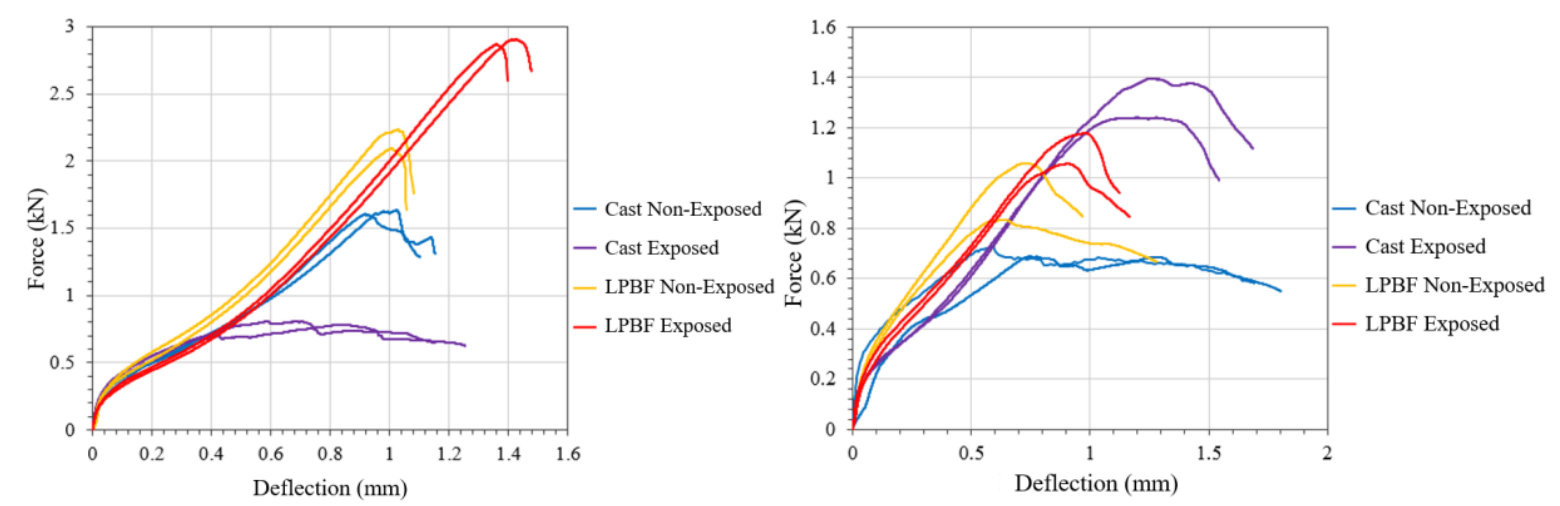

Figure 13. $F-D$ curves from SP tests performed on exposed and non-exposed C263 variants at a) room temperature and b) $780^{\circ} \mathrm{C}$.

Fracture surfaces from the SP tests are exhibited in Figure Figures 14 and 15. Macroscopic views of Cast C263 fractures from room temperature testing reveal differences in cracking behaviour bet ween exposed and non-exposed material. Figure 14a) shows a more ductile response displayed by the nonexposed variant compared with the exposed condition, as shown in Figure 14b). At higher magnifications, the Cast specimens demonstrated similar fracture surface appearances, with exposed Cast C263 arguably developing more pronounced micro-voids. Cracking regimes seem to be predominantly transgranular, with fractures from exposed material revealing some indication of the grain structure, suggesting a possibly mixed-mode fracture behaviour.

Fracture surfaces resulting from $780^{\circ} \mathrm{C} \mathrm{SP}$ testing, as shown in Figure 14c) and d), presented contrasting fracture behaviour to room temperature failures, mirroring the $F$ - $D$ results. A full opening of the fracture surface was observed in non-exposed Cast samples (Figure 14c)), which was not observed in the exposed condition (Figure 14d)). Nonetheless, fractures are similar in appearance at higher magnifications, larger micro-voids have formed resulting from ductile tearing in exposed C263 fracture surfaces.
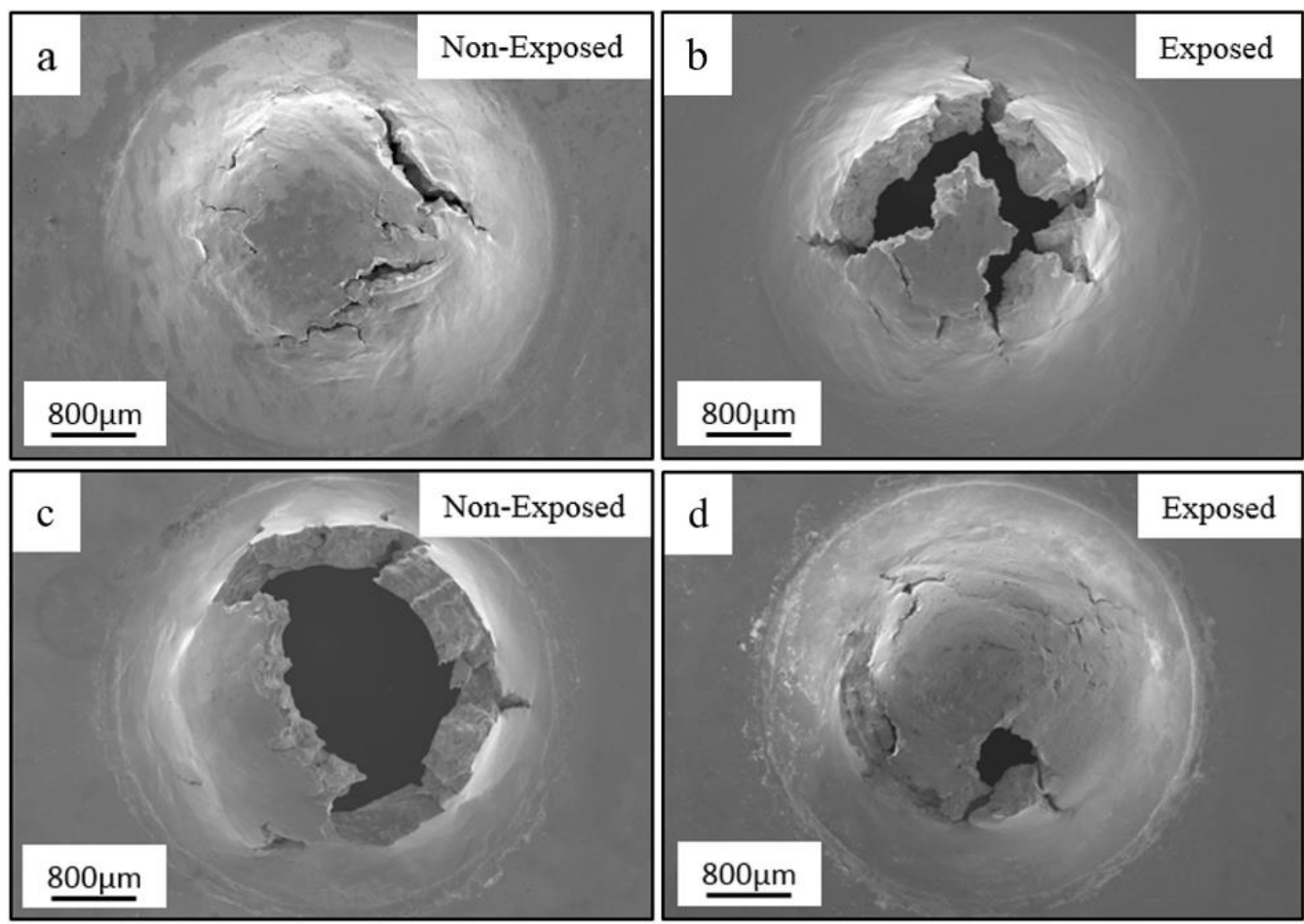

Figure 14. SP fracture surfaces from a) non-exposed and b) exposed room temperature SP testing and c) non-exposed and d) exposed SP testing at $780^{\circ} \mathrm{C}$ on Cast C263. 
The LPBF variants show similarities in fracture appearances as seen in the macroscopic fractographs in Figure 15, with both the exposed and non-exposed conditions displaying circumferential cracking when tested at room temperature. Microscopic views of these fracture surfaces present a very similar fracture behaviour, with both exhibiting a typically ductile transgranular failure regime with some influence from the overall grain structures. Similarities between exposed and non-exposed LPBF C263 extend out to fracture surfaces resulting from SP testing at $780^{\circ} \mathrm{C}$, as demonstrated in Figure $15 \mathrm{c}$ ) and d). Both variants exhibit circumferential and radial intergranular cracking.
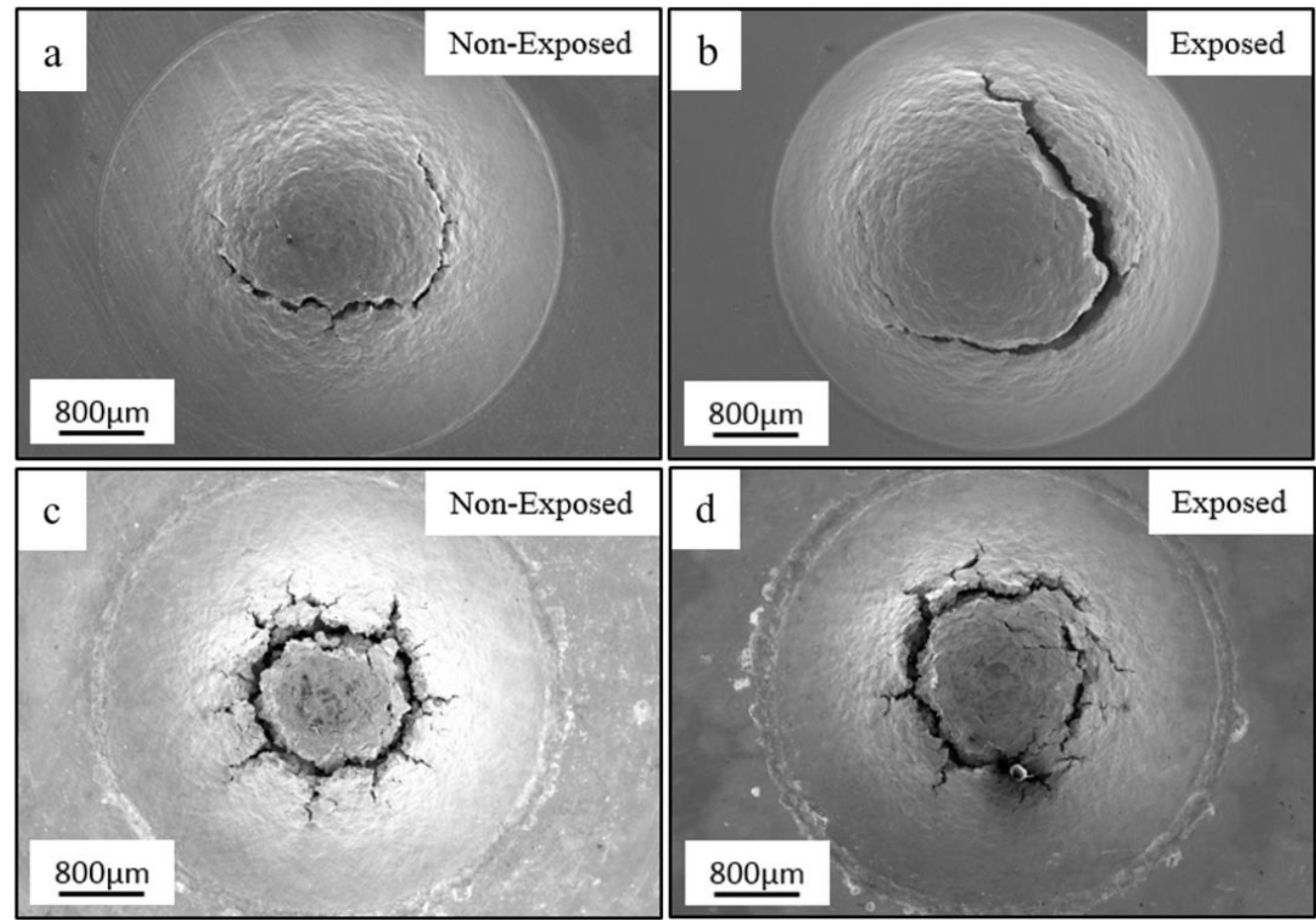

Figure 15. SP fracture surfaces from a) non-exposed and b) exposed room temperature SP testing and c) non-exposed and d) exposed SP testing at $780^{\circ} \mathrm{C}$ on LPBF C263.

As stated previously, at room temperature Cast $\mathrm{C} 263$ experienced a reduction in $F_{\max }$, contrasting with the behaviour of the LPBF variant, which saw an increase in $F_{\max }$ following thermal exposure. The mixed-mode fracture appearance of Cast C263 in the exposed condition suggests influences from features in both intergranular and intragranular regions. A development of acicular $\gamma$ '-depleting TCP phases, recognised as $\eta$-phase (Figure 8), were discovered in intragranular areas of exposed Cast grains; these were not found in the exposed LPBF variant. The presence of these phases, coupled with the regular appearance of TCP phases from the breakdown of grain boundary carbides would act to embrittle the material in these regions [16], [17], [21], encouraging mixed-mode fractures and a drop in mechanical performance. Whereas, in the LPBF material, only $\gamma^{\prime}$ coarsening was observed in intragranular regions with no evidence of TCP phase precipitation in these areas. Furthermore, the dominant failure mode was transgranular; with coarser $\gamma$ ' precipitates strengthening intragranular areas, this resulted in an increase in $F_{\max }$ due to thermal exposure following room temperature testing.

From the SP tests performed at $780^{\circ} \mathrm{C}$, Cast $\mathrm{C} 263$ experienced a significant increase in $F_{\max }$ following the exposure programme, whereas only a modest increase in strength was demonstrated in the LPBF variant. The factors which influenced the considerable improvement in Cast SP tensile strength included further coarsening of $\gamma^{\prime}$ to hinder movement of dislocations at higher temperatures, coarsening of carbides to prevent grain boundary sliding and an increase in measured grain size, although the latter cannot be considered a direct consequence from thermal exposure. In the exposed LPBF variant, a primarily intergranular fracture mode was displayed, as opposed to the mixed-mode failure which had been witnessed previously. Coarsening of $\gamma^{\prime}$ precipitates and importantly the presence of $\mathrm{M}_{23} \mathrm{C}_{6}$ carbides in the exposed condition would positively impact the mechanical response at this test temperature [16], [22]. Nonetheless, considering that a purely intergranular failure was observed, this suggests a grain 
boundary weakening effect caused by TCP phases which have formed in several grain boundary regions existed [17], limiting the increase in $F_{\max }$ caused by other influences.

\section{Conclusions}

The effect of thermal exposure at representative in-service conditions has been evaluated for the nickel base superalloy C263. The study was undertaken on the LPBF manufactured version of the material and compared against the traditionally Cast equivalent. From this research, the following conclusions can be made:

- Exposing Cast and LPBF C263 samples to service temperatures for an extended period of time resulted in microstructural and chemical alterations, which influenced their mechanical performance, as assessed via the SP test.

- $\quad \gamma^{\prime}$ coarsening was evident in both variants, however, intragranular $\gamma^{\prime}$ depleting TCP phases was only noticed in the exposed Cast material, developing through the breakdown of $\gamma^{\prime}$. This behaviour was not seen in the LPBF material as a fully developed array of $\gamma^{\prime}$ precipitation was not present in the non-exposed condition.

- SP test results revealed contrasting behaviours between the Cast and LPBF C263 materials. At room temperature, Cast $\mathrm{C} 263$ experienced a reduction in $F_{\max }$, contrasting with the behaviour of the LPBF variant, which saw an increase in $F_{\max }$ following thermal exposure. Conversely, at $780^{\circ} \mathrm{C}$, the exposed Cast material offered a superior response. This behaviour is thought to be related to the development of $\eta$-phase in the Cast material, which acts to embrittle the alloy at low temperatures, and the coarsening of $\gamma^{\prime}$ precipitates and the presence of $\mathrm{M}_{23} \mathrm{C}_{6}$ carbides in the exposed condition, which would positively impact the mechanical response at elevated temperatures.

- The thermal exposure programme has demonstrated that with the precipitation of $\mathrm{M}_{23} \mathrm{C}_{6}$ carbides in various areas of the exposed LPBF variant, a microstructure akin to wrought C263 can be achieved from an AM version of the material, if the heat treatment programme is further altered.

\section{Author contribution}

The research presented in this paper was carried out as a collaboration between all authors. The research theme was defined by Robert Lancaster, Spencer Jeffs and Sean Davies. Sean Davies and Mark Coleman performed the SEM and EBSD analysis. Sean Davies, David Lewis and Robert Lancaster provided the interpretation of the microstructural features. Spencer Jeffs and Sean Davies performed the mechanical testing. Robert Lancaster, Sean Davies, Spencer Jeffs, Mark Coleman and David Lewis co-worked on the discussion and interpretation of the results with respect to the material's microstructure. All authors have contributed to, edited and approved the final manuscript.

\section{Acknowledgements}

The current research was funded under the EPSRC Rolls-Royce Strategic Partnership in Structural Metallic Systems for Gas Turbines (grants EP/H500383/1 and EP/H022309/1). The provision of materials and technical support from Rolls-Royce plc. is gratefully acknowledged.

We would like to acknowledge the assistance provided by Swansea University College of Engineering Advanced Imaging and Microscopy (AIM) Facility, which was funded in part by the EPSRC (EP/M028267/1), The European Regional Development Fund through the Welsh Government (80708) and the Ser Solar project via the Welsh Government.

\section{References}

[1] T. DebRoy, H. L. Wei, J. S. Zuback, T. Mukherjee, J. W. Elmer, J. O. Milewski, A. M. Beese, 
A. Wilson-Heid, A. De, and W. Zhang, "Additive manufacturing of metallic components Process, structure and properties," Prog. Mater. Sci., vol. 92, pp. 112-224, 2018.

[2] J. J. Lewandowski and M. Seifi, "Metal Additive Manufacturing: A Review of Mechanical Properties," Аnnu. Rev. Mater. Res., vol. 46, no. 1, pp. 151-186, 2016.

[3] W. E. Frazier, "Metal additive manufacturing: A review," J. Mater. Eng. Perform., vol. 23, no. 6, pp. 1917-1928, 2014.

[4] N. C. Ferreri, S. Ghorbanpour, S. Bhowmik, R. Lussier, J. Bicknell, B. M. Patterson, and M. Knezevic, "Effects of build orientation and heat treatment on the evolution of microstructure and mechanical properties of alloy Mar-M-509 fabricated via laser powder bed fusion," Int. J. Plast., vol. 121, no. May, pp. 116-133, 2019.

[5] F. Zhang, L. E. Levine, A. J. Allen, M. R. Stoudt, G. Lindwall, E. A. Lass, M. E. Williams, Y. Idell, and C. E. Campbell, "Effect of heat treatment on the microstructural evolution of a nickelbased superalloy additive-manufactured by laser powder bed fusion," Acta Mater., vol. 152, pp. 200-214, 2018.

[6] S. J. Davies, S. P. Jeffs, M. P. Coleman, and R. J. Lancaster, "Effects of heat treatment on microstructure and creep properties of a laser powder bed fused nickel superalloy," Mater. Des., vol. 159, pp. 39-46, Dec. 2018.

[7] C. M. F. Rae and R. C. Reed, "The precipitation of topologically close-packed phases in rhenium-containing superalloys," Acta Mater., vol. 49, pp. 4113-4125, 2001.

[8] N. El-Bagoury and Q. Mohsen, "Gamma prime and TCP phases and mechanical properties of thermally exposed nickel-base superalloy," Phase Transitions, vol. 84, no. 11-12, pp. 11081122, 2011.

[9] J. X. Yang, Q. Zheng, X. F. Sun, H. R. Guan, and Z. Q. Hu, “Topologically close-packed phase precipitation in a nickel-base superalloy during thermal exposure," Mater. Sci. Eng. A, vol. 465, no. 1-2, pp. 100-108, 2007.

[10] CEN Workshop Agreement CWA 15267, "European Code of Practise: Small Punch Test Method for Metallic Materials.” 2007.

[11] M. Bruchhausen, T. Austin, S. Holmstrom, E. Altstadt, P. Dymacek, S. Jeffs, R. Lancaster, R. Lacalle, K. Matocha, and J. Petzova, "European standard on small punch testing of metallic materials," in Proceedings of the ASME 2017 Pressure Vessels and Piping Conference, 2017, vol. 1 A.

[12] F. J. Humphreys and M. Hatherly, Recrystallisation and Related Annealing Phenomena, 2nd ed. Elsevier Ltd, 2004.

[13] S. Cruchley, H. Evans, and M. Taylor, "An overview of the oxidation of Ni-based superalloys for turbine disc applications: surface condition, applied load and mechanical performance," Mater. High Temp., vol. 33, no. 4-5, pp. 465-475, 2016.

[14] F. S. Pettit and G. H. Meier, "Oxidation and Hot Corrosion of Superalloys," Superalloys 1984 Fifth Int. Symp., pp. 651-687, 1984.

[15] D. T. S. Lewis, R. G. Ding, M. T. Whittaker, P. M. Mignanelli, M. C. Hardy, "The effect of oxidising thermal exposures on the fatigue properties of a polycrystalline powder metallurgy nickel-based superalloy," Mater. De., vol. 189, Apr. 2020.

[16] M. J. Donachie and S. J. Donachie, Superalloys A Technical Guide. 2002.

[17] T. M. Pollock and S. Tin, "Nickel-Based Superalloys for Advanced Turbine Engines: Chemistry, Microstructure and Properties," J. Propuls. Power, vol. 22, no. 2, pp. 361-374, 2006.

[18] R. C. Reed, The Superalloys: Fundamentals and Applications. Cambridge University Press, 2006.

[19] X. Dong, X. Zhang, K. Du, Y. Zhou, T. Jin, and H. Ye, "Microstructure of Carbides at Grain Boundaries in Nickel Based Superalloys," J. Mater. Sci. Technol., vol. 28, no. 11, pp. 10311038, 2012.

[20] I. S. Kim, B. G. Choi, H. U. Hong, J. Do, and C. Y. Jo, "Influence of thermal exposure on the microstructural evolution and mechanical properties of a wrought Ni-base superalloy," Mater. Sci. Eng. A, vol. 593, pp. 55-63, 2014.

[21] W. Z. Wang, H. U. Hong, I. S. Kim, B. G. Choi, H. W. Jeong, M. Y. Kim, and C. Y. Jo, "Influence of $\gamma^{\prime}$ and grain boundary carbide on tensile fracture behaviors of Nimonic 263," Mater. Sci. Eng. A, vol. 523, no. 1-2, pp. 242-245, 2009. 
[22] ASM International, "High-Temperature Behavior of Nickel-Base Superalloys," in ASM Specialty Handbook: Heat-Resistant Materials, Illustrate., J. R. Davis, Ed. ASTM International, 1997, pp. 230-235. 